\title{
Association between clinically diagnosed lumbar intervertebral disc prolapse and magnetic resonance image findings
}

\author{
Md. Habibur Rahman, K. M. Tarikul Islam, Md. Rokibul Islam, Moududul Haque, Haradhon \\ Devnath, Mohammad Afzal Hossain and Kanak Kanti Barua
}

\begin{abstract}
Article Info
Department of Neurosurgery, Faculty of Surgery, Bangabandhu Sheikh Mujib Medical University, Shahbag, Dhaka, Bangladesh

For Correspondence: K. M. Tarikul Islam dr.tarik_2007@yahoo.com

Received:

Accepted:

Available Online: $\quad 5$ September 2016

ISSN: 2224-7750 (Online) 2074-2908 (Print)

DOI: $10.3329 /$ bsmmuj.v9i3.29459

Cite this article:

Rahman MH, Islam KMT, Islam MR, Haque M, Devnath $H$, Hossain MA, Barua KK. Association between clinically diagnosed lumbar intervertebral disc prolapse and magnetic resonance image findings. Bangabandhu Sheikh Mujib Med Univ J. 2016; 9: 146-150.

Available at:

www.banglajol.info

A Journal of Bangabandhu Sheikh Mujib Medical University, Dhaka, Bangladesh

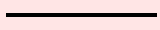

\section{Abstract} not have any clinical significance.

\section{Introduction}

One of the commonest causes of low back pain among working people is the lumbar intervertebral disc prolapse. 1 The clinically significant sciatica due to disc prolapse is $4-6 \% .2$ In $85 \%$ of cases, no specific diagnosis can be made. Only $1-3 \%$ have lumbar disc herniation. 3

Lumbar intervertebral disc prolapse can be diagnosed clinically by low back pain and its radiation along the course of the sciatic nerve, commonly called sciatica. Usually, it is a shooting, episodic pain related to movement, and going down the back of the thigh to a varying distance to the posterior or posterolateral aspect of the calf and the foot, the radiating pain is aggravated by coughing, sneezing or straining and relieved by rest (particularly in supine position which reduces the intradiscal pressure). An important feature of disc prolapse is the intermittent exacerbation and remission of varying duration and severity of low back pain. Besides radiating pain, there may also be paraesthesia (tingling or numbness), in the area of distribution of particular nerve root. 4
\end{abstract}

There are contradictory reports on the findings of magnetic resonance image (MRI) in lumbar intervertebral disc prolapse. A study was conducted on 54 patients using 3 of 4 clinical criteria (low back pain with radiation down to the lower limbs, radicular pain along specific dermatomes, positive straight leg raising test, presence of neurological symptoms and signs e.g. motor or sensory deficit and MRI of lumbosacral spine of the respondent). Evaluation of MRI of lumbosacral spine was done based on extent of disc prolapse, disc degeneration, nerve root compression neural foramen compromise. The logistic regression analysis between the findings of MRI and the clinical features show that there was a significant association in the neural foramen or lateral recess (Odd's ratio 7.106, $p<0.05)$, the root compression $(p<0.01)$ as well as the disc extrusion $(p<0.05)$. There was no statistical association between clinical levels and other MRI findings like disc protrusion and disc bulge ( $\mathrm{p}$ value 0.21 and 0.14 , respectively). The strength of agreement between clinical and MRI diagnosis level of disc prolapse was calculated using kappa statistics (kvalue). The test revealed a very good agreement for $\mathrm{L} 3 / 4(\mathrm{k}$-value $=0.812)$ and good agreement for L4/5 and L5/SI level (k-value 0.75 and 0.75 respectively) between these two procedures, suggesting that level of disc prolapse could be correctly diagnosed without MRI findings. In conclusion, clinically diagnosed levels associate well with MRI levels, but all MRI abnormalities do

The findings identified by the magnetic resonance imaging (MRI) can confirm the clinical suspicions of lumbar intervertebral disc prolapse. Prophylactic or therapeutic intervention should not be done based on MRI abnormal findings in the absence of clinical indicators. .5

An important finding is the loss of disc height. However, the bulge or the protrusion of the disc bulge does not have any additional significance. 6 The presence of any extrusion of the disc or severe degree nerve compression at one or more sites is associated with the pain at the distal leg.?

There is a good correlation between the findings of clinical features and MRI. However, all MRI abnormalities do not correlate with the findings of clinical features. The presence of centrolateral protrusion of the disc and the extrusion with gross neural foramen compromise are associated with the clinical features. Bulging of the disc with compression of thecal sac or central protrusions and extrusions without significant neural foramen compromise are clinically insignificant. The presence of 
neural foramen is important in determining the clinical features while the type of disc herniation correlates poorly with the clinical features. When the disc lesions are at multiple levels with the neural foramen compromise, the patient is likely to have neurological deficit. 1

Various studies have correlated clinical findings with MRI findings and these studies also gave contrasting reports and were inconclusive. Association of many anatomic variations (degeneration of disc, bulging of the disc and spinal stenosis) with symptoms remains speculative. The correlation of physical findings with MRI remains a critical part of the diagnosis of low back pain and radiculopathy. So, we need to study the association between clinically diagnosed lumbar intervertebral disc prolapse and MRI findings and to know about its significance in decision making for treatment and in predicting prognosis.

\section{Materials and Methods}

This observational cross- sectional study was conducted on 54 consecutive patients with a clinical diagnosis of prolapse lumbar intervertebral disc irrespective of age, sex, and occupation who were admitted for surgery at the Department of Neurosurgery, Bangabandhu Sheikh Mujib Medical University from April 2011 to November 2012. Patients with 3 of 4 clinical criteria were included in this study: Low back pain with radiation down to the lower limbs, radicular pain along specific dermatomes, positive straight leg raising test, the presence of neurological symptoms and signs e.g. motor or sensory deficit and MRI of the lumbosacral spine of the respondent. Exclusion criteria were a)

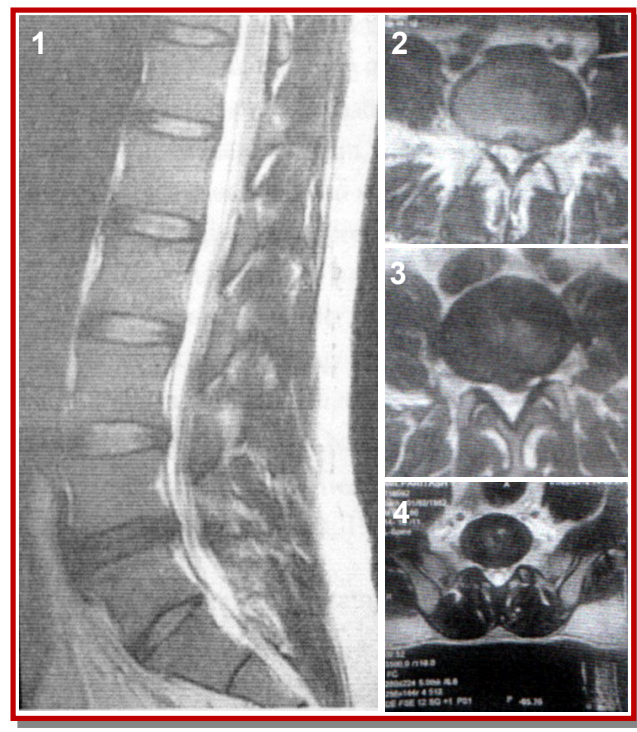
patients with acute onset of symptoms for $<3$ weeks, b) radicular symptoms for the first time and c) history of previous lumbar spine surgery. On admission, all the patients were evaluated by taking detailed history thorough general and neurological examination with particular attention to lower limbs. Each patient was evaluated for the distribution of pain and the presence of neurological features. The distribution of pain at the dermatomal level was pointed out.

Evaluation of MRI of the lumbosacral spine including Figure 1: MRI of degenerated disc at L4/5 (1), degeneration of the disc, the extruded disc (2), protruded disc (3) and bulge extent of disc prolapse, disc (4) ssion, neural foramen compromise, and other findings (hypertrophy of ligamentum flavum or facet joint, spondylolisthesis, stenosis of the canal) were done (Figure 1).

Data was collected by structured questionnaire to collect necessary information. Informed written consent was taken from each participant or guardian before data collection. Data was analyzed by using software SPSS (statistical package for social science), version 16 .

\section{Results}

Of the 54 patients, $88.9 \%$ were in between $21-60$ years. About three-fourth $(74.1 \%)$ of the patients were male and one-fourth $(25.9 \%)$ were female giving a male to female ratio of roughly $3: 1$. Fifteen $(27.8 \%)$ patients were service holder and 14 (25.9\%) patients were day-laborer, housewife and businessman both were $11(20.4 \%)$ in number and student was $3(5.6 \%)$ cases.

Over $80 \%$ patients with MRI findings of protrusion or extrusion of disc with nerve root compression had symptomatic levels $(95.5 \%$ and $81.2 \%$ respectively) while $80 \%$ of patients with a bulge of disc and nerve root contact/compression had symptomatic levels. Extrusion of the disc with foramen/lateral recess compromise produced symptomatic levels in $100 \%$ cases, while foramen/ lateral recess compromise in disc bulge and protrusion produced symptomatic levels in some patients $(33.3 \%$ and $50 \%$ respectively) (Table I) When there was no evidence of foramen/lateral recess compromise, these levels were asymptomatic despite the type of herniation of the disc. In fact, the patient with gross extrusion but with central position and not compromising neural foramen were asymptomatic.

MRI findings were analyzed with logistic regression analysis for association of clinical levels for Odd's ratio and clinical significance (Table II). Logistic regression analysis for association between MRI findings and clinical levels show that there was significant association between evidence of neural foramen/lateral recess compromise as seen in MRI and clinical levels (Odd's ratio 7.1, $\mathrm{p}<0.05$ ); between evidence of root compression seen in MRI and clinical levels $(p<0.001)$ as well as between evidence of disc extrusion seen in MRI and clinical levels $(p<0.05)$. There was no statistically significant association between clinical levels and other MRI findings such as bulging and protrusion of the disc ( $\mathrm{p}$ value 0.21 and 0.14 respectively).

The strength of agreement between the clinical and MRI diagnosis of prolapse of the disc was calculated using kappa statistics (k-value) (Table III). The test was found to have a very good agreement for the $\mathrm{L} 3 / 4$ level $(\mathrm{k}$-value $=0.812)$ and good 
Table I

Association between the type of disc herniaiton and clinical levels

\begin{tabular}{|llcc|}
\hline $\begin{array}{l}\text { Type of herni- } \\
\text { ation }\end{array}$ & Neural canal compromise & $\begin{array}{c}\text { Symptomatic } \\
\text { levels }\end{array}$ & $\begin{array}{c}\text { Asympto- } \\
\text { matic levels }\end{array}$ \\
\hline $\begin{array}{l}\text { Disc } \\
\text { bulge }\end{array}$ & $\begin{array}{l}\text { Without neural foramen } \\
\text { compromise (TSC) }\end{array}$ & 2 & 25 \\
& $\begin{array}{l}\text { With foramen/lateral } \\
\text { recess compromise }\end{array}$ & 4 & 8 \\
& $\begin{array}{l}\text { Nerve root contact/ } \\
\text { compression }\end{array}$ & 4 & 1 \\
$\begin{array}{l}\text { Disc } \\
\text { protrusion }\end{array}$ & $\begin{array}{l}\text { Without neural foramen } \\
\text { compromise (TSC) }\end{array}$ & 0 & 0 \\
$\begin{array}{l}\text { With foramen/lateral } \\
\text { recess compromise }\end{array}$ & 7 & 7 \\
$\begin{array}{l}\text { Nerve root contact/ } \\
\text { compression }\end{array}$ & 26 & 6 \\
\hline $\begin{array}{l}\text { Without neural foramen } \\
\text { extrusion }\end{array}$ & $\begin{array}{l}\text { compromise (TSC) } \\
\text { With foramen/lateral } \\
\text { recess compromise }\end{array}$ & 1 & 0 \\
\hline $\begin{array}{l}\text { Nerve root contact/ } \\
\text { compression }\end{array}$ & 21 & 0 \\
\hline
\end{tabular}

Table II

Association between clinical levels and MRI findings

\begin{tabular}{|lrrr|}
\hline MRI findings & Odd's ratio & $95 \%$ CI interval & p value \\
\hline Disc bulge & 3.060 & $0.532-17.596$ & 0.210 \\
Disc protrusion & 5.098 & $0.586-44.355$ & 0.140 \\
$\begin{array}{l}\text { Disc extrusion } \\
\begin{array}{l}\text { Foramen/lateral recess } \\
\text { compromise }\end{array}\end{array}$ & 28.456 & $1.506-537.494$ & 0.026 \\
$\begin{array}{l}\text { Nerve root contact/ } \\
\text { compression }\end{array}$ & 33.822 & $1.196-42.381$ & 0.031 \\
\hline
\end{tabular}

agreement for the L4/5 and L5/S1 level (k-value 0.795 and 0.705 respectively). These suggest that level of prolapse of the disc could be correctly diagnosed without the findings of MRI.

\section{Discussion}

Lumbar disc protrusions are more frequent in middle-aged people from third to the fifth decade of life. The herniation of the lumbar disc is more common at L4/5 and L5/S1. Less than $5 \%$ of it occurs at $\mathrm{Ll} / 2, \mathrm{~L} 2 / 3$ and $\mathrm{L} 3 / 4$. Fracture of intravertebral disc may occur following injury. earliest symptom of the root involvement in a lumbar disc prolapse is radiating pain along the sciatic nerve (sciatica). $\underline{4}$

The incidence of lumbar disc herniation under 24 years of age is only $1-3.5 \% .9,10$ In our study, $3.7 \%$ of PLID patients were under 20 years of age. It was reported that male patient was $75 \%$ and the female patient was $25 \%$ which is similar to our study where the male patient was $74.1 \%$ and the female patient was $25.9 \% . \underline{11}$ In our study, service holders (included government and non-government job) and day-laborer $(27.8 \%$ and $25.9 \%$ respectively) more commonly presented with PLID which is comparable to another study. $\underline{11}$ Professional, housewife and clerical also develop PLID.

According to most literature, the common presentation of lumbar disc herniation was low back pain and sciatica. Low back pain was reported in $99 \%$ cases and leg pain/sciatica in $79 \%$ cases. 12 In our study, all the cases presented with low back pain and sciatica. Right sciatica was found in $46.3 \%$ of cases whereas left sciatica was in $37.0 \%$ cases. Bilateral sciatica was present in $16.7 \%$ patients which are nearly similar to another study. $\underline{13}$ Right sciatica was in $51.0 \%$, left sciatica in $43 \%$ and bilateral sciatica in $6 \%$ of the PLID cases.

The presence of weakness in one or both extensor hallucis longus was reported by $42.9 \%$ participants, $35 \%$ reported the sensation of pin and needles and $37.4 \%$ reported numbness 7 and sphincter dysfunction was present in $6.2 \%$ cases. 2 In our study, 33\% patients reported weakness in extensor hallucis longus and $81.5 \%$ presented with tingling sensation/numbness and $7.4 \%$ with urinary incontinence. These were probably due to late presentation of patients in our department for surgery.

The positive straight leg raising test means is the involvement of nerve root. This test is usually positive in all levels of herniation (94\%). .13 Strongly positive test (under $30^{\circ}$ ) means that there is more frequently herniation in the lower discs. In our study, over $61 \%$ exhibited positive straight leg raising test $\left(>30-80^{\circ}\right)$ and over $11.1 \%$ were strongly positive straight leg raising test $\left(<30^{\circ}\right)$.

It was reported that quadriceps weakness was present in $15(62.5 \%)$ cases $\underline{\mathbf{1 4}}$ and weak dorsiflexion of foot in $16(32.8 \%)$ cases, weak ankle-planter flexion in $1(1.9 \%)$ and weak EHL in $6(11.43 \%)$ cases. $\underline{15}$ In our study, EHL was weak in $63 \%$ cases, weak ankle planter-flexion in $31.5 \%$ cases, ankledorsiflexion in $22.3 \%$ cases and knee extensor weakness in $5(9.3 \%)$ cases.

In our study knee jerk was diminished in 5.6\% cases and ankle jerk in $50 \%$ cases which is nearly similar to another study where diminished knee jerk was present in $4 \%$ cases and diminished ankle jerk in $46 \%$ cases. 11 


\begin{tabular}{|c|c|c|c|c|}
\hline \multicolumn{5}{|c|}{ Table III } \\
\hline \multicolumn{5}{|c|}{$\begin{array}{l}\text { Strength of agreement between clinical and MRI diagnosis levels } \\
\qquad(\mathrm{n}=54)\end{array}$} \\
\hline \multirow[t]{2}{*}{$\begin{array}{l}\text { Clinical diagnosis } \\
\text { level }\end{array}$} & \multicolumn{2}{|c|}{ MRI diagnosis level } & k-value & $\begin{array}{l}\text { Strength of } \\
\text { agreement }\end{array}$ \\
\hline & Yes & No & & \\
\hline \multicolumn{5}{|l|}{ For L3/4 disc level } \\
\hline Yes & 5 & 1 & \multirow[t]{2}{*}{0.812} & \multirow[t]{2}{*}{ Very good } \\
\hline No & 1 & 47 & & \\
\hline \multicolumn{5}{|l|}{ For L4/5 disc level } \\
\hline Yes & 33 & 1 & 0.795 & \multirow[t]{2}{*}{ Good } \\
\hline No & 4 & 16 & 0.795 & \\
\hline \multicolumn{5}{|l|}{ For L5/S1 disc level } \\
\hline Yes & 23 & 6 & 0.705 & \multirow[t]{2}{*}{ Good } \\
\hline No & 2 & 23 & 0.705 & \\
\hline
\end{tabular}

The different dermatomes were checked to find out the level of prolapse disc after asking about the pain radiation. There is a debate about the sensibility of the patient with lumbar disc herniation. The presence of a reduction in sensibility in such patients varies between 21 and $88 \% . \underline{16}$ The present study showed that the sensory disturbance is most common at SI dermatome which corresponds with other studies. Out of 54 patients, $43(79.6 \%)$ patients had the sensory deficit and $11(20.4 \%)$ patients had no sensory deficit. The level of disc herniation was determined on the clinical basis.

In the study of Cheung, the most commonly affected level was found to be the L5/S1 (52\%), whereas L4/5 was the second most affected level and L1/2 was the least commonly affected level.17 In our study, results were similar where most commonly affected levels were L4/5 (83.3\%) intervertebral disc, second most were L5/S1 (70.4\%) disc followed by L3/4, $\mathrm{L} 2 / 3$ and $\mathrm{Ll} / 2$ level in 44.4, 22.2 and $13.0 \%$ respectively.

It was reported that disc bulge was present in $15 \%$, protrusion in $31.25 \%$ and non-contained herniation/extrusion in $44.4 \%$. 17 In our study, disc bulge was found in $38.9 \%$, protrusion in $40.7 \%$ and extrusion in $20.4 \%$ levels of disc herniation.

The clinical features and the MRI findings of the level of disc prolapse correlate well which might not be considered as essential for the clinical diagnosis. But MRI is mandatory when someone is planned for surgery. Not all the lesions identified in MRI have symptoms. Out of 113 levels of disc lesions, only 65 were symptomatic. However, MRI is a sensitive test for identifying disc lesions but it is not specific. MRI finding with neural foramen compromise and nerve root compression are likely to be more symptomatic than those without neural foramen compromise.
It was reported that a centrolateral disc extrusions, disc protrusions, and disc bulge with neural foramen compromise are more likely to cause symptoms in that order while central disc protrusions and extrusions, as well as disc bulges without foramen compromise, are less likely to produce symptoms. When a nerve root compression is visible on MRI, it is more likely to produce symptoms as in $86.4 \%$ (57 out of 66 patients) patients: when only neural foramen compromise was seen, $39.5 \%$ patients were symptomatic and without neural foramen compromise only $11.9 \%$ patients were symptomatic. This clearly shows that MRI evidence of nerve root compression is more likely to produce symptoms. 1 In our study, MRIvisible nerve root contact/compression produce symptomatic levels in $86.4 \%$ (51 out of 59 levels), with foramen/lateral recess compromise produce symptomatic levels in $44.4 \%$ and those without neural foramen compromise (TSC) produce sympto -matic levels in $7.4 \%$ cases, which is almost similar to above study finding.

In the study of Janardhana et al, 15 patients out of 119 had ligament flavum hypertrophy. 18 Thirty four patients with stenosis of the canal, 19 patients with facet joint hypertrophy ( 1 or more levels), and 5 patients had spondylolisthesis.1 In our study, 39 patients had canal stenosis, ligamentum flavum hypertrophy found in $22(40.7 \%)$ patients, facets hypertrophy in $33(61.5 \%)$ patients and spondylolisthesis in $6(11.2 \%)$ patients nearly similar to above study.

MRI is a helpful preoperative diagnostic investigation which shows structural changes in the discs, the size and the site of the extrusion or protrusion. However, these images are not useful in predicting neurological deficit and therefore should not be used as an indication for surgery unless there is a strong correlation with the clinical findings. 19 In our study, $34(63.0 \%)$ patients had signs and symptoms of PLID at the level L4/5, 53.7\% at L5/S1 and $11.1 \%$ cases at L3/4 level; which on MRI was found to be $68.5 \%, 46.3 \%$ and $11.1 \%$ respectively, showing good agreement for L4/5 and L5/S1 (k-value 0.795 and 0.705 respectively) and very good agreement for L3/4 level ( $\mathrm{p}$ value 0.812), between the two modalities of diagnosis in detecting level of disc prolapse. MRI detected herniation at an L2/3 level in 1 case which could not diagnose clinically. So for evaluation of high lumbar disc prolapse, MRI is very essential.

\section{Conclusion}

Clinically diagnosed level of lumbar intervertebral disc prolapse associates well with the MRI findings. But all MRI abnormalities do not have a clinical significance. 


\section{References}

1. Janardhana AP, Rajagopal, Rao S, Kamath A. Correlation between clinical features and magnetic resonance imaging findings in lumbar disc prolapse. Indian J Orthop. 2010; 44: 263-69.

2. Akbar A, Mahar A. Lumbar disc prolapse: Management and outcome analysis of 96 surgically treated patients. J Pakistan Med Assoc. 2002; 52: 62-65.

3. Greenberg MS. Spine and spinal cord. In: Handbook of neurosurgery. 7th ed. New York, Thieme, 2010.

4. Goel A, Pandaya S. Lumbar disc protrusion. In: Textbook of neurosurgery. Ramamurti B, Tandon PN (eds). 2nd ed. New Delhi, Churchill Livingstone, 1996.

5. Borenstein DG, O'Mara JWJR, Boden SD, Lauerman WC, Jacobson A, Platenberg C, Schellinger D, Wiesel SW. The value of magnetic resonance imaging of the lumbar spine to predict low-back pain in asymptomatic subjects: A sevenyear follow-up study. J Bone Joint Surg Am. 2001; 83: 1306-11.

6. Milette Pc, Fontaine S, Lepanto L, Cardinal E, Breton G. Differentiating lumbar disc protrusions, disc bulges, and discs with normal contour but abnormal signal intensity, magnetic resonance imaging with discographic correlations. Spine (Phila PA 1976) 1999; 24: 44-53.

7. Beattie PF, Meyers SP, Stratford P, Millard RW, Hollenberg GM. Associations between patient report of symptoms and anatomic impairment visible on lumbar magnetic resonance imaging. Spine (Phila PA 1976) 2000; 25: 819-28.

8. Ahsan M, Sakeb N, Zaman N, Nur-E-Jannat S. Management of traumatic spinal column injury: A tertiary hospital experience. Bangabandhu Sheikh Mujib Med Univ J. 2015; 8: 95-104.

9. Fisher RG, Saunders RL. Lumbar disc protrusion in children. J Neurosurg. 1981; 54: 480-83.
10. Kumar R, Kumar V, Das NK, Behari S, Mahapatra AK. adolescent lumbar disc disease: Findings and outcome. Childs Nerv Syst. 2007; 23: 1295-99.

11. Weir BK. Prospective study of 100 lumbosacral discectomies. J Neurosurg. 1979; 50: 283-89.

12. Pappas CT, Harrington T, Sonntag VK. Outcome analysis in 654 surgically treated lumbar disc herniations. Neurosurgery 1992; 30: 862-66.

13. Kortelainen P, Puranen J, Koivisto E, Lahde S. Symptoms and signs of sciatica and their relation to the localization of the lumbar disc herniation. Spine (Phila PA 1976) 1985; 10: 88-92.

14. Abdullah AF, Ditto EW, Byrd EB, Williams R. Extreme-lateral lumbar disc herniations, clinical syndrome and special problems of diagnosis. J Neurosurg. 1974; 41: 229-34.

15. Jensen $\mathrm{OH}$. The level-diagnosis of a lower lumbar disc herniation: The value of sensibility and motor testing. Clin Rheumatol. 1987; 6: 564-69.

16. Peeters GG, Aufdemkampe G, Oostendorp RA Sensibility testing in patients with a lumbosacral radicular syndrome. J Manipulative Physiol Ther. 1998; 21: 81-88.

17. Cheung KM, Karppinen J, Chan Dhodw, Song YQ, Sham P, Cheah KS, Leong JC, Luk KD. Prevalence and pattern of lumbar magnetic resonance imaging changes in a population study of one thousand forty-three individuals. Spine (Phila PA 1976) 2009; 34: 934-40.

18. Karppinen J, Malmivaara A, Tervonen O, Paakko E, Kurunlahti M, Syrjala P, Vasari P, Vanharanta $\mathrm{H}$. Severity of symptoms and signs in relation to magnetic resonance imaging findings among sciatic patients. Spine (Phila PA 1976) 2001; 26: 49-54.

19. Wittenberg RH, Lutke A, Longwitz D, Greskotter KH, Willburger RE, Schmidt K, Plafki C, Steffen R. The correlation between magnetic resonance imaging and the operative and clinical findings after lumbar microdiscectomy. Int Orthop. 1998; 22: 241-44. 